\title{
Conservative Management of Pituitary Macroadenoma Contacting the Optic Apparatus
}

\author{
Won Hyung A. Ryu, Samantha Tam, Brian Rotenberg, Mohamed Ahmed Labib, \\ Donald Lee, David A. Nicolle, Stan Van Uum, Neil Duggal
}

\begin{abstract}
Objectives: To describe the tumor characteristics and visual function in conservatively managed patients with nonfunctioning pituitary macroadenoma (NFMA) that contacted/compressed the visual pathway. Design: Retrospective case-series. Setting: Tertiary-care academic institution.Participants: Six patients with diagnosis of NFMA. Main Outcome: Visual function and radiological characteristics of the optic apparatus and pituitary tumor. Results: All patients had radiological evidence of optic apparatus compression but only one had visual field defect at the initial presentation. While two of the six patients developed visual field changes during followup $(41 \pm 34.8$ months $)$, the patient with visual field defect at the time of diagnosis improved to normal vision. Conclusions: Select NFMAs that contact the optic apparatus, without visual dysfunction, may be managed with close ophthalmological and radiographic monitoring, depending on tumor and imaging characteristics. This may be of particular relevance in patients considered to have a high peri-operative risk, such as advanced age or significant co-morbidities.
\end{abstract}

RÉSUMÉ: Traitement conservateur des macro adénomes pituitaires en contact avec l'appareil optique. Objectifs : Le but de l'étude était de décrire les caractéristiques des tumeurs et la fonction visuelle chez les patients atteints de macro adénomes pituitaires non fonctionnels (MANF) adjacents ou comprimant les voies optiques, traités de façon conservatrice. Méthodologie : Il s'agit d'une étude rétrospective portant sur six patients ayant consulté dans une institution académique de soins tertiaires, chez qui un diagnostic de MANF a été posé. L'issue primaire était la fonction visuelle et les caractéristiques radiologiques de l'appareil optique et de la tumeur pituitaire. Résultats : Tous les patients avaient une compression de l'appareil optique à l'imagerie, mais seulement un avait un déficit du champ visuel au moment de la première évaluation. Deux des six patients ont présenté des changements du champ visuel au cours du suivi (41 $\pm 34,8$ mois) ; le patient qui avait un déficit du champ visuel au moment du diagnostic a recouvré une vision normale. Conclusions : Certains MANF qui touchent à l'appareil optique sans provoquer de dysfonction visuelle peuvent être suivis étroitement en ophtalmologie et en radiologie, selon les caractéristiques de la tumeur et de l'imagerie. Ceci peut être particulièrement pertinent chez les patients considérés à haut risque périopératoire, tels les patients âgés ou qui ont des comorbidités importantes.

Can. J. Neurol. Sci. 2010; 37: 837-842

Non-functioning pituitary macroadenoma (NFMA) is the most prevalent type of pituitary tumor, accounting for approximately $15 \%$ of all pituitary tumors. Even with such prevalence, current understanding of the natural history of nonfunctioning pituitary macroadenoma remains controversial ${ }^{1,2}$. Two publications on conservatively managed NFMA are limited by heterogeneous patient cohort (e.g. combining macro and microadenomas), and a small number of patients with actual visual pathway involvement (e.g. contact with optic chiasm, optic nerve, or optic tract). Karavitaki et al (2007) studied the natural history of 40 patients with non-functioning pituitary adenomas, of which 16 were microadenoma and do not distinguish the number of macroadenoma cases with actual chiasm compression ${ }^{3}$. The only information regarding mass effect was that three patients had developed new chiasm involvement and, in these patients, surgical decompression was carried out. Similarly, Dekker et al (2007) examined 28 nonsurgical NFMA patients but only $2 / 28$ patients were noted to have compression of the chiasm ${ }^{4}$.
While the gold standard of treatment for NFMA with significant visual impairment is surgery, little consensus exists for managing patients with NFMA who have mild or no visionrelated complaints ${ }^{5}$. In this setting, surgery has been suggested as a preventative measure in visually asymptomatic patients with

From the Shulich School of Medicine \& Dentistry (WHAR), Department of Otolaryngology - Head and Neck Surgery (BR), Department of Clinical Neurosciences - Division of Neurosurgery (MAL, ND), Department of Diagnostic Radiology and Nuclear Medicine (DL), Department of Ophthalmology (DAN), Department of Medicine - Division of Endocrinology and Metabolism (SVU), University of Western Ontario, London; Queen's University, School of Medicine (ST), Kingston, Ontario, Canada.

Received January 14, 2010. Final Revisions Submitted April 28, 2010. Correspondence to: Neil Duggal, Department of Clinical Neurological Sciences, (Division of Neurosurgery), University of Western Ontario, 339 Windermere Road, London, Ontario, N6A 5A5, Canada. 
radiological evidence of optic chiasm compression or tumor approximating the chiasm ${ }^{5}$. In contrast, other published reports suggest that slight contact between NFMA and chiasm may not be predictive of future visual dysfunction ${ }^{6-8}$. To our knowledge, no studies have specifically looked at a cohort of conservatively managed patients with confirmed tumor contact with the optic apparatus. The objective of this study was therefore to describe the changes in tumor characteristics and visual function in conservatively managed patients with NFMA that contacted/ compressed the visual pathway, but did not have significant visual impairment.

\section{Methods}

This study was approved by the University of Western Ontario Research Ethics Board. Records of 245 consecutive patients with a parasellar/intrasellar mass between 2000 and 2008 from the Clinical Neurological Sciences Department (Division of Neurosurgery) in London Health Sciences Centre, (a tertiary care academic institution in London, Ontario, Canada), were retrospectively reviewed. Of the 245 patients, 122 were of pituitary macroadenoma, of which 84 patients underwent surgical decompression, 13 were medically treated and 25 were conservatively managed. From the cohort of conservatively managed patients, six individuals met the following inclusion criteria: (1) new radiological diagnosis of NFMA, (2) conservative management of NFMA, (3) access to good quality magnetic resonance imaging (MRI) confirming contact between the tumor and optic apparatus, (4) serial visual field assessments by a neuroophthalmologist. Non-functioning pituitary adenoma was defined as pituitary adenoma with maximal diameter greater than $10 \mathrm{~mm}$ and simultaneous absence of hormonal overproduction.

During the course of their work-up, all included patients had been clinically reviewed by the interdisciplinary pituitary team consisting of endocrinologists, neuroophthalmologists, neuroradiologists, neurosurgeons, and otolaryngologists. After the initial referral, if deemed to not be an operative candidate the patients were reviewed every 6-12 months by serial MRI imaging, endocrinological assessment and formal visual field testing. Currently, pituitary surgery is reserved for patients with visual dysfunction, hormonally-active tumors refractory to medical treatment, or cases where patients cannot tolerate medical management. In this group of patients, all but one had visual symptoms. The one patient with visual dysfunction (Case 6) declined surgery and elected for conservative management. Endocrinology investigations included measurements of cortisol, TSH, Free T4 and Free T3, LH, FSH, testosterone or estradiol, prolactin, and Insulin Growth Factor-1. Neuroophthalmological evaluation included visual field (Goldmann or/and Humphrey Automated perimetry), pupillary response to light and visual acuity. The presence of ophthalmoplegia, afferent pupillary defect, optic disc pallor, papilledema and ptosis were described if present. All MRI studies were done using 1.5T scanner and were reviewed by a neuroradiologist and a neurosurgeon. There were minor differences in the imaging sequences, but all MRI examinations included T1-weighted and T2-weighted sequences for coronal and sagittal planes. The MRI scans were reviewed for tumor and optic apparatus imaging characteristics, locations of contact between NFMA and the optic apparatus and presence of cavernous sinus invasion. The tumor characteristics included maximum height, height at maximum chiasm compression, transverse diameter (width on coronal plane), anteroposterior (AP) diameter (width on sagittal plane), density of tumor, and site of compression. The tumor location was categorized as prefixed, central or postfixed relative to the optic chiasm using the sagittal T1 and coronal T2 weighted sequences.

The chiasmal contact characteristics included two different measures of chiasm elevation (our study method and Frisen \& Jensen method), as well as thickness of chiasm at maximum compression $^{6-8}$. For our study method, the neuroradiologist measured chiasm elevation by connecting the most inferolateral aspects of the chiasm (standard line) and measuring the perpendicular distance between the standard line and the inferior aspect of the chiasm at maximum compression (Figure 1). In contrast, Frisen and Jensen defined chiasm height as the midline distance between the optic nerve canal plane and the inferior aspect of the chiasm ${ }^{7}$.

\section{RESULTS}

Of the 25 conservatively managed patients, six patients had a diagnosis of NFMA with radiologically identified involvement of the optic apparatus and met the meeting inclusion/exclusion criteria. We included one woman and five males, the mean age at initial presentation was $66 \pm 6$.4years. Reasons for referral to the pituitary group specialists included seizure, chronic headache, dizziness, vertigo, muscle weakness in proximal limb, anorexia and incidental discovery of sellar mass. Mean duration

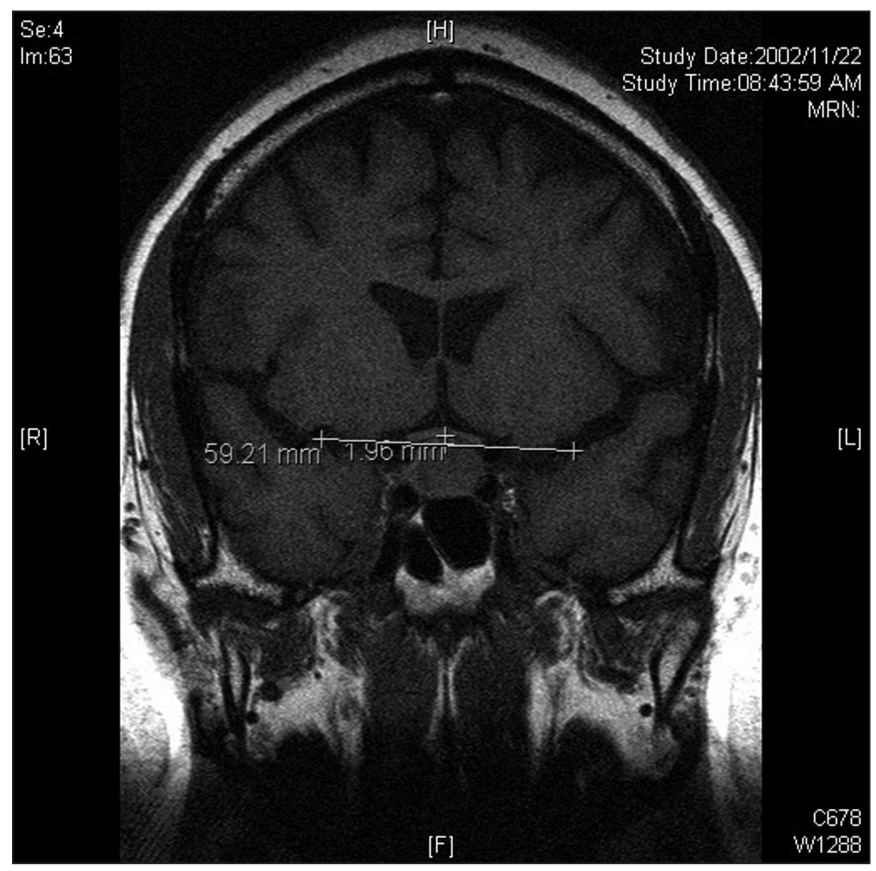

Figure 1: MR image of Case \#1 at the time of diagnosis showing NFMA contacting the optic chiasm with an example of chiasm elevation measurement. 
Table 1: Patient characteristics at initial presentation

\begin{tabular}{|c|c|c|c|c|c|c|c|c|c|c|c|c|}
\hline \multirow{2}{*}{$\begin{array}{l}\text { Pt } \\
\text { No. }\end{array}$} & \multirow{2}{*}{$\begin{array}{l}\text { Age (y)/ } \\
\text { Sex }\end{array}$} & \multicolumn{6}{|c|}{ Tumor characteristics } & \multicolumn{3}{|c|}{ Chiasm characteristics } & \multicolumn{2}{|c|}{ Visual function } \\
\hline & & $\mathrm{H}(\mathrm{mm})$ & $\begin{array}{l}\mathrm{HC} \\
(\mathrm{mm})\end{array}$ & $\begin{array}{l}\mathrm{T} \\
(\mathrm{mm})\end{array}$ & $\begin{array}{l}\text { AP } \\
(\mathrm{mm})\end{array}$ & Density & $\begin{array}{l}\text { Site of } \\
\text { compression }\end{array}$ & $\begin{array}{l}\mathrm{E} \\
(\mathrm{mm})\end{array}$ & $\begin{array}{l}\text { E (mm; } \\
\text { Frisen } \\
\text { method) }\end{array}$ & $\mathrm{W}(\mathrm{mm})$ & $\mathrm{VF}$ & VA \\
\hline 1 & $60 / \mathrm{M}$ & 14.3 & 14.5 & 17.6 & 14.8 & Heterogeneous & Chiasm & 2 & 1.6 & 1.2 & Normal & $\begin{array}{l}\mathrm{L} 20 / 30 \\
\mathrm{R} 20 / 20\end{array}$ \\
\hline 2 & $72 / \mathrm{F}$ & 11.4 & 11.4 & 16.0 & 14.0 & Heterogeneous & Chiasm & 0.4 & 0 & 1.6 & Normal & $\begin{array}{l}\mathrm{L} 20 / 25 \\
\mathrm{R} 20 / 25 \\
\end{array}$ \\
\hline 3 & $62 / \mathrm{M}$ & 20.4 & 22.5 & 27.1 & 18.4 & Heterogeneous & $\begin{array}{l}\text { Chiasm \& optic } \\
\text { nerve }\end{array}$ & 3 & 3.6 & 1.5 & Normal & $\begin{array}{l}\mathrm{L} 20 / 30 \\
\mathrm{R} 20 / 25 \\
\end{array}$ \\
\hline 4 & $60 / \mathrm{M}$ & 14.1 & 14.1 & 16.0 & 14.2 & Solid & Chiasm & 1.6 & 3.6 & 1.6 & Normal & $\begin{array}{l}\mathrm{L} 20 / 25 \\
\mathrm{R} 20 / 25 \\
\end{array}$ \\
\hline 5 & $65 / \mathrm{M}$ & 15.5 & 14.5 & 16.1 & 14.6 & Heterogeneous & Chiasm & 2.7 & 4.3 & 1.4 & Normal & $\begin{array}{l}\mathrm{L} 20 / 20 \\
\mathrm{R} 20 / 20\end{array}$ \\
\hline 6 & $75 / \mathrm{M}$ & 23.5 & 23.9 & 23.6 & 18.0 & Solid & $\begin{array}{l}\text { Chiasm \& optic } \\
\text { nerve }\end{array}$ & 1.1 & 5.0 & 1.3 & $\begin{array}{l}\text { R superior field } \\
\text { defect }\end{array}$ & $\begin{array}{l}\mathrm{L} 20 / 25 \\
\mathrm{R} 20 / 25\end{array}$ \\
\hline
\end{tabular}

Abbreviations: $\mathrm{H}$ indicates maximum height; $\mathrm{HC}$, height at maximum compression; T, transverse diameter; AP, anterioposterior diameter; E, elevation; W, thickness at maximum compression; VF, visual field; VA, visual acuity; L, left eye; R, right eye.

between onset of symptom and first specialist visit was $5.2 \pm 3.6$ months. The patient characteristics at initial presentation are summarized in Table 1. All six patients had radiological evidence of optic apparatus involvement at time of diagnosis but only one patient had simultaneous significant neuro-ophthalmological finding. One patient had left eye ptosis dating back to childhood. Mean follow-up period was $41 \pm 34.8$ months. All six patients in this study had a pre-fixed tumor. No evidence of optic nerve atrophy was found for all six patients during the study period, but one patient (Case 6) was found to have slightly thinned left optic nerve on MRI. Also, every patient had normal optic nerve and optic tract signal intensity on MRI. The patient characteristics at the last follow-up visit are summarized in Table 2. Two of the five patients developed visual field changes during the course of the management, detected at the last follow-up visit (46 months and 14 months after diagnosis). The patient with visual field defect at diagnosis (Case 6) was noted to have worsening visual field defect during the early follow-up period but recovered (without any intervention based on the patient's refusal for surgery) to full visual field at the last follow-up visit.

\section{Case examples}

Case 1: A 60-year-old male, was found to have a sellar mass during clinical investigation of seizure. Initial ophthalmological examination demonstrated visual acuity of RE: 20/20 and LE: 20/30 as well as normal Goldmann perimetry visual fields. The remaining neuroophthalmological exam was non-significant. The MRI revealed a heterogeneously enhancing lesion contacting a pre-fixed chiasm. The lesion demonstrated imaging characteristics consistent with pituitary macroadenoma including a height of $14.3 \mathrm{~mm}$, height at maximum compression of $14.5 \mathrm{~mm}$, transverse diameter of $17.6 \mathrm{~mm}$ and AP diameter of $14.8 \mathrm{~mm}$. The chiasm was compressed and elevated by $2 \mathrm{~mm}$, a
Frisen \& Jensen elevation measurement of $1.6 \mathrm{~mm}$, and a thickness at maximum compression of $1.2 \mathrm{~mm}$. The MRI showed signs of cavernous sinus involvement. At the last follow-up visit, 105 months since initial presentation, the patient's visual acuity was RE: 20/20. and LE: 20/20. Neuroophthalmological exam was normal including automated perimetry visual fields. The MRI at eight years following the initial presentation continued to show a heterogeneous pituitary macroadenoma with a height of $14.1 \mathrm{~mm}$, height at maximum compression of $13.4 \mathrm{~mm}$, transverse diameter of $18.3 \mathrm{~mm}$ and AP diameter of $15.5 \mathrm{~mm}$. The chiasm characteristics included elevation of $1.4 \mathrm{~mm}$, Frisen \& Jensen elevation measurement of $1.8 \mathrm{~mm}$, and thickness at maximum compression of $1.4 \mathrm{~mm}$. No signal change was seen in the structures of the visual apparatus (Figure 1).

Case 5: A 65-year-old male, was found to have an incidental sellar mass. Initial ophthalmological examination demonstrated visual acuity of RE: 20/20 and LE: 20/20 as well as normal Goldmann perimetry visual fields. The remaining neuroophthalmological exam was non-significant. The MRI revealed heterogeneously enhancing lesion contacting a pre-fixed chiasm. The lesions demonstrated imaging characteristics consistent with pituitary macroadenoma including a height of $15.5 \mathrm{~mm}$, height at maximum compression of $14.5 \mathrm{~mm}$, transverse diameter of $16.1 \mathrm{~mm}$ and AP diameter of $14.6 \mathrm{~mm}$. The chiasm was compressed and elevated by $2.7 \mathrm{~mm}$, a Frisen \& Jensen elevation measurement of $4.3 \mathrm{~mm}$, and a thickness at maximum compression of $1.4 \mathrm{~mm}$. The MRI showed signs of cavernous sinus involvement. At the last follow-up visit, 14 months since initial presentation, the patient's visual acuity was RE: 20/25 and LE: 20/20. Automated perimetry revealed right temporal visual field change. Remaining neuroophthalmological exam was normal. The MRI at one year following the initial presentation continued to show a heterogeneous pituitary macroadenoma 
Table 2: Patient characteristics at last follow-up

\begin{tabular}{|c|c|c|c|c|c|c|c|c|c|c|c|c|}
\hline \multirow[t]{2}{*}{ Pt No. } & \multirow{2}{*}{$\begin{array}{l}\text { Follow- } \\
\text { up (m) }\end{array}$} & \multicolumn{6}{|c|}{ Tumor characteristics } & \multicolumn{3}{|c|}{ Chiasm characteristics } & \multicolumn{2}{|c|}{ Visual function } \\
\hline & & $\begin{array}{l}\mathrm{H} \\
(\mathrm{mm})\end{array}$ & $\begin{array}{l}\mathrm{HC} \\
(\mathrm{mm})\end{array}$ & $\begin{array}{l}\mathrm{T} \\
(\mathrm{mm})\end{array}$ & $\mathrm{AP}(\mathrm{mm})$ & Density & $\begin{array}{l}\text { Site of } \\
\text { compression }\end{array}$ & $\begin{array}{l}\mathrm{E} \\
(\mathrm{mm})\end{array}$ & $\begin{array}{l}\mathrm{E}(\mathrm{mm} ; \\
\text { Frisen } \\
\text { method) }\end{array}$ & $\begin{array}{l}\mathrm{W} \\
(\mathrm{mm})\end{array}$ & $\mathrm{VF}$ & VA \\
\hline 1 & 105 & 14.1 & 13.4 & 18.3 & 15.5 & Heterogeneous & Chiasm & 1.4 & 1.8 & 1.4 & Normal & $\begin{array}{l}\mathrm{L} 20 / 20 \\
\mathrm{R} 20 / 20\end{array}$ \\
\hline 2 & 46 & 14.4 & 14.1 & 18.8 & 16.3 & Heterogeneous & Chiasm & 1.6 & 1.2 & 1.2 & $\begin{array}{l}\mathrm{R} \text { homonymous } \\
\text { change }\end{array}$ & $\begin{array}{l}\mathrm{L} 20 / 25 \\
\mathrm{R} 20 / 25\end{array}$ \\
\hline 3 & 17 & 23.4 & 23.2 & 26.9 & 19.7 & Heterogeneous & $\begin{array}{l}\text { Chiasm \& optic } \\
\text { nerve }\end{array}$ & 3.7 & 8.4 & 1.3 & Normal & $\begin{array}{l}\mathrm{L} 20 / 30 \\
\mathrm{R} 20 / 25\end{array}$ \\
\hline 4 & 17 & 14.1 & 14.1 & 14.8 & 14.8 & Solid & Chiasm & 1.4 & 5.6 & 1.4 & Normal & $\begin{array}{l}\mathrm{L} 20 / 25 \\
\mathrm{R} 20 / 25\end{array}$ \\
\hline 5 & 14 & 16.8 & 15.2 & 17.2 & 15.2 & Heterogeneous & Chiasm & 3.2 & 8.1 & 1.4 & $\mathrm{R}$ temporal change & $\begin{array}{l}\mathrm{L} 20 / 20 \\
\mathrm{R} 20 / 25\end{array}$ \\
\hline 6 & 49 & 29.5 & 27.0 & 26.0 & 18.0 & Solid & $\begin{array}{l}\text { Chiasm \& optic } \\
\text { nerve }\end{array}$ & 2.1 & 9.0 & 1.2 & Normal & $\begin{array}{l}\mathrm{L} 20 / 25 \\
\mathrm{R} 20 / 25\end{array}$ \\
\hline
\end{tabular}

Abbreviations: $\mathrm{H}$ indicates maximum height; $\mathrm{HC}$, height at maximum compression; T, transverse diameter; AP, anterioposterior diameter; E, elevation; W, thickness at maximum compression; VF, visual field; VA, visual acuity.

with a height of $16.8 \mathrm{~mm}$, height at maximum compression of $15.2 \mathrm{~mm}$, transverse diameter of $17.2 \mathrm{~mm}$ and AP diameter of $15.2 \mathrm{~mm}$. The chiasm characteristics included elevation of $3.2 \mathrm{~mm}$, Frisen \& Jensen elevation measurement of $8.1 \mathrm{~mm}$ and thickness at maximum compression of $1.4 \mathrm{~mm}$. No signal change was seen in the structures of the visual apparatus (Figure 2).

Case 6: A 75-year-old male, was found to have an incidental sellar mass during clinical investigation of muscle weakness in the proximal limb and anorexia. Initial ophthalmological examination demonstrated visual acuity of RE: 20/25 and LE: $20 / 25$ as well as right superior temporal field defect by Goldmann perimetry. The remaining neuro-ophthalmological exam was non-significant. The MRI revealed solid tumor contacting a pre-fixed chiasm. The lesion demonstrated imaging characteristics consistent with pituitary macroadenoma including a height of $23.5 \mathrm{~mm}$, height at maximum compression of $23.9 \mathrm{~mm}$, transverse diameter of $23.6 \mathrm{~mm}$ and AP diameter of $18.0 \mathrm{~mm}$. The chiasm was compressed and elevated by $1.1 \mathrm{~mm}$, Frisen \& Jensen elevation measurement of $5.0 \mathrm{~mm}$, and a thickness at maximum compression of $1.3 \mathrm{~mm}$. The MRI showed signs of cavernous sinus involvement. At the last follow-up visit, 49 months since initial presentation, the patient's visual acuity was RE: 20/25 and LE: 20/25. Goldmann perimetry revealed normal visual fields. Remaining neuroophthalmological exam was normal. The MRI at four years following the initial presentation continued to show a heterogeneous pituitary macroadenoma with a height of $29.5 \mathrm{~mm}$, height at maximum compression of $27.0 \mathrm{~mm}$, transverse diameter of $26.0 \mathrm{~mm}$ and AP diameter of $18.0 \mathrm{~mm}$. The chiasm characteristics included elevation of $2.1 \mathrm{~mm}$, Frisen \& Jensen elevation measurement of
$9.0 \mathrm{~mm}$ and thickness at maximum compression of $1.2 \mathrm{~mm}$. No signal change was seen in the structures of the visual apparatus (Figure 3).

\section{Discussion}

The most common indication for pituitary surgery is visual dysfunction stemming from mass effect. Growing evidence suggests that there is considerable variability in the degree of visual dysfunction ${ }^{7,9}$. Given that the relationship between optic apparatus deformation and visual symptom is still not fully understood, the natural history of macroadenoma continues to be a topic of importance. We report on a series of conservatively managed patients with confirmed contact between a NFMA and the optic apparatus, thus enabling a demonstration of the natural history of the tumor.

This study highlights the variability in the sensitivity of visual apparatus to the compressive effect of NFMA. At the time of diagnosis, five of six patients with chiasmal deformation had normal neuroophthalmological examinations. At the last followup Case 3 with second largest chiasm elevation $(8.4 \mathrm{~mm}$ by Frisen \& Jensen method), did not show any vision deterioration while Case 5 with similar chiasm deformation $(8.1 \mathrm{~mm}$ by Frisen $\&$ Jensen method) had developed visual field deficits. Moreover, one patient's (Case 6) visual field normalized during course of management even though the tumor had actually increased in size with further chiasmal deviation. Similar variability in the clinical consequence of mass effect is seen in the literature. For example, a published study on the natural course of NFMA reported six patients with visual field defects without any chiasm involvement ${ }^{4}$. In contrast, a number of researchers have reported 


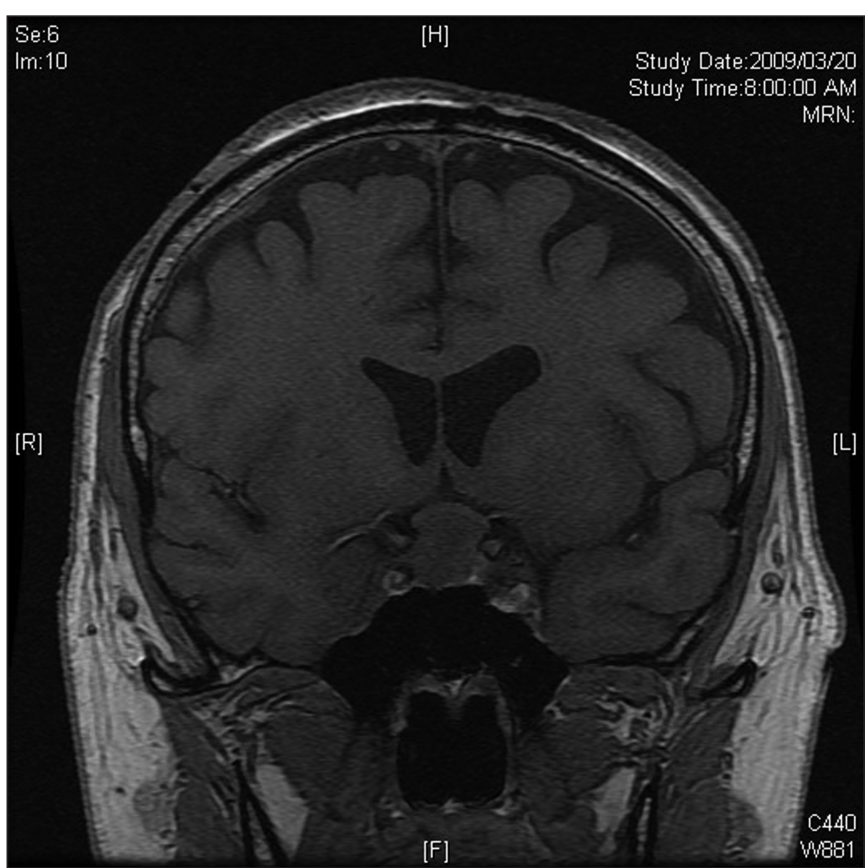

Figure 2: MR image of Case \#5 at the time of last follow-up continuing to show NFMA compressing the optic chiasm.

the robustness of the optic chiasm to dislocation/compression from to NFMA contact ${ }^{6-8}$. The relationship between tumor mass effect and progression of visual dysfunction may be more complex than the linear relationship that some reports have previously suggested ${ }^{10,11}$

One possible variable influencing the sensitivity of the optic apparatus to mass effect is the location of tumor relative to the chiasm (e.g. pre-fixed, central, post-fixed). Eda et al reported that while centrally located tumor (labelled as superior type) showed a relationship between tumor size and visual field defect, pre-fixed and post-fixed tumors did not show such relationship ${ }^{12}$. All six patients in this study had a pre-fixed tumor. Another potential variable influencing the severity of mass effect is the rate of tumor growth. Specifically, NFMA with fast suprasellar extension will lead to a sudden chiasm deformation and prevent the chiasm from adequately compensating ${ }^{7}$. Tumor density may also influence the severity of mass effect with tumors of high density leading to a greater compressive force than a cystic tumor. These disparate findings may represent a single spectrum of consequences of mass effect influenced by multiple variables such as tumor location, growth rate of tumor, tumor density, and vulnerability of optic apparatus. Clinically, such variability in visual deterioration creates difficulty in determining the optimal management plan for patients with NFMA; surgical resection versus conservative follow-up.

For patients with marked visual dysfunction, surgery is the gold standard of treatment to maintain or improve visual function. However, indication for surgical treatment over conservative management is not as clear cut for the subset of

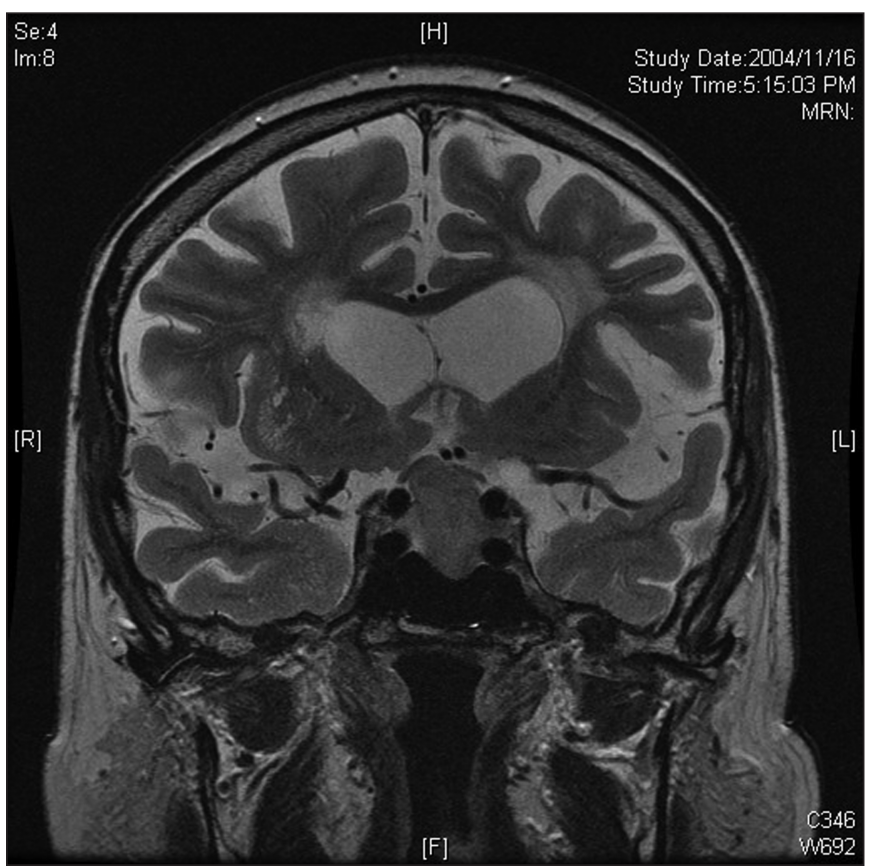

Figure 3: MR image of Case \#6 at the time of diagnosis showing NFMA displacing the optic chiasm.

NFMA patients without significant complaints or minimally symptomatic patients with significant co-morbidities ${ }^{3,13,14}$. In an attempt to better standardize the clinical practice strategies for NFMA, Dekkers et al 2008 provided evidence-based algorithm for managing NFMA with emphasis on neuroophthalmological and radiological findings 5 . One of the proposed indicators for surgery in this model was tumor approximating the optic chiasm $^{5}$. Based on this guideline, all of the patients in this study would have undergone surgery even though five of six patients lacked visual deterioration at initial presentation. Given the previously mentioned studies that report the resilience of the chiasm against deformation, this proposed indicator may actually engender premature exposure to surgery and the accompanying potential peri-operative complications ${ }^{15-17}$.

Radiological evidence of proximity or mere contact between tumor and the optic apparatus without contemporaneous visual dysfunction should not be the only indicator for surgery. One important reason for this is the number of variables in the imaging technique that can influence the extent of compression of the chiasm seen. For instance, Frisen \& Jenson utilized the midline distance between the extrapolated optic nerve canal plane and the inferior aspect of the chiasm to define chiasm elevation ${ }^{7}$. A potential issue of this method is the difficulty of relating the height of the chiasm to the optic canal in coronal sections given that head tilt would affect the extrapolated position of that plane. Conversely, using the sagittal plane requires the optic canal to be clearly identified, which is rarely achieved. Establishing a standardized method of measuring the tumor and chiasm characteristics that addresses such technical 
variability may help in clarifying the relationship between radiological evidence and clinical manifestation of mass effect.

The major source of limitation in the study stems from the non-standardized MRI examination specifications. Also, given that the magnitude of measurements used in the study are in millimetres, the value of the tumor and chiasm characteristics may have been altered if the patient's head position was off axis. However, we do not think that precise standardization of the sequences would have altered the findings of chiasmal contact, which was the main inclusion criterion for the study. Furthermore, given that only one neuroradiologist reviewed the MR images, we were not able to analyze the inter-rater variability. Another limitation of our study is the small sample size, preventing statistical analysis and limiting the external validity of this study. Lastly, given the relatively short follow-up for some patients, they may develop visual field defects in the future.

Treatment decision for asymptomatic NFMA patients should be made on individual basis taking into account age, degree of optic apparatus involvement, visual dysfunction, rate/direction of tumor growth, pituitary function and patient preference. It is important to recognize the need for regular assessments in conservatively managed patients to minimize the potential negative consequences of mass effect.

\section{Conclusion}

An important component in determining the optimal treatment strategy for NFMA is clarifying the relationship between the imaging characteristics of tumor, visual pathway involvement and the extent of decline in visual function. Our study highlights the variability in the sensitivity of the visual apparatus to compression/dislocation. Based on our results, along with supporting existing literature, we propose that for NFMA patients with confirmed chiasm compression but normal neuroophthalmological exam, conservative management with close radiographic and neuroophthalmological monitoring is a reasonable option in selected cases.

\section{ACKNOWLEDGEMENT}

Won Hyung A. Ryu was supported by Schulich Research Opportunity Program from University of Western Ontario. The authors thank the participating hospital, and our research coordinator: Izabela Kowalczyk.

\section{REFERENCES}

1. Daly AF, Rixhon M, Adam C, Dempegioti A, Tichomirowa MA, Beckers A. High prevalence of pituitary adenomas: a crosssectional study in the province of Liege, Belgium. J Clin Endocrinol Metab. 2006;91(12):4769-75.

2. Surawicz TS, McCarthy BJ, Kupelian V, Jukich PJ, Bruner JM, Davis FG. Descriptive epidemiology of primary brain and CNS tumors: results from the Central Brain Tumor Registry of the United States, 1990-1994. Neurooncol. 1999;1(1):14-25.

3. Karavitaki N, Collison K, Halliday J, et al. What is the natural history of nonoperated nonfunctioning pituitary adenomas? Clin Endocrinol (Oxf). 2007;67(6):938-43.

4. Dekkers OM, Hammer S, de Keizer RJ, et al. The natural course of non-functioning pituitary macroadenomas. Eur J Endocrinol. 2007;156(2):217-24

5. Dekkers OM, Pereira AM, Romijn JA. Treatment and follow-up of clinically nonfunctioning pituitary macroadenomas. J Clin Endocrinol Metab. 2008;93(10):3717-26.

6. Ikeda $\mathrm{H}$, Yoshimoto $\mathrm{T}$. Visual disturbances in patients with pituitary adenoma. Acta Neurol Scand. 1995;92(2):157-60.

7. Frisen L, Jensen C. How robust is the optic chiasm? Perimetric and neuro-imaging correlations. Acta Neurol Scand. 2008;117(3): 198-204.

8. Fujimoto N, Saeki N, Miyauchi O, Adachi-Usami E. Criteria for early detection of temporal hemianopia in asymptomatic pituitary tumor. Eye. 2002;16(6):731-8.

9. Karanjia N, Jacobson DM. Compression of the prechiasmatic optic nerve produces a junctional scotoma. Am J Ophthalmol. 1999; 128(2):256-8.

10. Huang WC, Lee LS. Visual field defects in patients with pituitary adenomas. Chung Hua I Hsueh Tsa Chih (Taipei). 1997;60(5): 245-51.

11. Carrim ZI, Reeks GA, Chohan AW, Dunn LT, Hadley DM. Predicting impairment of central vision from dimensions of the optic chiasm in patients with pituitary adenoma. Acta Neurochir (Wien). 2007;149(3):255-60.

12. Eda M, Saeki N, Fujimoto M, Sunami K. Demonstration of the optic pathway in large pituitary adenoma on heavily T2 weighted MR image. Brit J Neurosurg. 2002;16(1): 21-9.

13. Reincke M, Allolio B, Saeger W, Menzel J, Winkelmann W. The 'incidentaloma' of the pituitary gland. Is neurosurgery required? JAMA. 1990;263(20):2772-6.

14. Freda PU, Wardlaw SL. Clinical review 110: diagnosis and treatment of pituitary tumors. J Clin Endocrinol Metab. 1999;84(11):3859-66.

15. Dusick JR, Esposito F, Mattozo CA, Chaloner C, McArthur DL, Kelly DF. Endonasal transsphenoidal surgery: the patient's perspective-survey results from 259 patients. Surg Neurol. 2006; 65(4):332-41.

16. Fatemi N, Dusick JR, de Paiva Neto MA, Kelly DF. The endonasal microscopic approach for pituitary adenomas and other parasellar tumors: a 10-year experience. Neurosurgery. 2008;63 (4 Suppl 2):244-56.

17. White DR, Sonnenburg RE, Ewend MG, Senior BA. Safety of minimally invasive pituitary surgery (MIPS) compared with a traditional approach. Laryngoscope. 2004;114(11):1945-8. 